\title{
ENSINAR-APRENDER A CUIDAR DE FERIDAS: EXPERIÊNCIA DE ENFERMEIRAS ESTAGIÁRIAS DOCENTES*
}

Telma Elisa Carraro ${ }^{1}$, Luciara Fabiane Sebold ${ }^{2}$, Silvana Silveira Kempfer ${ }^{3}$, Ariane Thaise Frello, Mariely Carmelina Bernardi ${ }^{5}$

RESUMO: A realização de estágio docência é um quesito instituído para bolsistas da Coordenação de Aperfeiçoamento de Pessoal de Nível Superior e Conselho Nacional de Desenvolvimento Científico e Tecnológico. Este texto objetiva narrar a experiência de ensinar-aprender a cuidar de feridas, vivenciada por quatro pós-graduandas de enfermagem durante a realização de seus estágios docência, em uma instituição pública de ensino superior do sul do Brasil. O estágio ocorreu de agosto a dezembro de 2010 e foi desenvolvido na disciplina de Fundamentos para o Cuidado Profissional do curso de Graduação em Enfermagem da mesma universidade. Considerou-se como um momento importante de aprendizagem nos contextos tutoria em sala de aula, prática em laboratório de enfermageme em hospital onde o ensinare aprender estiveram intimamente relacionados. A experiência proporcionou a ampliação dos olhares para a formação em enfermagem.

PALAVRAS-CHAVE: Educação em enfermagem; Cuidados de enfermagem; Processos fisiológicos da pele; Estágio clínico.

\section{TEACHING-LEARNING WOUND CARE: THE EXPERIENCE OF TRAINEE TEACHERS OF NURSING}

ABSTRACT: The carrying out of a teaching placement is a requirement for scholarship students of the Coordination for Perfection of Higher Education Staff and the National Council for Scientific and Technological Development. This text aims to relate the experience of teaching-learning wound care, as experienced by four post-graduate students during their teaching placements, in a public higher education institution in the South of Brazil. The placement took place from August to December 2010 in the Basics of Professional Care course, part of the same university's undergraduate nursing course. It was considered an important learning stage in the contexts tutorship in the classroom, and laboratory and hospital practice, where teaching and learning are very closely linked. The experience permitted a widening of understanding concerning nursing training.

KEYWORDS: Nursing education; Nursing care; Physiological processes in skin; Clinical placement.

\section{ENSEÑAR-APRENDER A CUIDAR DE HERIDAS: EXPERIENCIA DE ENFERMERAS EN PRÁCTICAS DOCENTES}

RESUMEN: La realización de prácticas de docencia es un requisito instituido para becarios de la Coordinación de Perfeccionamiento de Personal de Nivel Superior y Consejo Nacional de Desarrollo Científico y Tecnológico. Este texto objetiva narrar la experiencia de enseñaraprender a cuidar de heridas, vivida por cuatro posgraduandas de enfermería durante la realización de sus prácticas de docencia, en una institución pública de enseñanza superior del sur de Brasil. Las prácticas ocurrieron de agosto a diciembre de 2010 y fueon desarrolladas en la disciplina de Fundamentos para el Cuidado Profesional del curso de Graduación en enfermería de la misma universidad. Se consideró un momento importante de aprendizaje en los contextos tutoría en aula de clase, práctica en laboratorio de enfermería y en hospital donde el enseñary aprender estuvieron relacionados de modo íntimo. La experiencia ha proporcionado más atención para la formación en enfermería. PALABRAS-CLAVE: Educación en enfermería; Cuidados de enfermería; Procesos fisiológicos de la piel; Prácticas clínicas.

\footnotetext{
* Relato de experiência vivenciado por alunas de mestrado e doutorado, a partir da disciplina do Programa de Pós-Graduação em Enfermagem da Universidade Federal de Santa Catarina- UFSC, intitulado "Estágio de Docência”, em 2010.
}

${ }^{1}$ Enfermeira. Doutora em Enfermagem. Professora do Departamento de Enfermagem e do Programa de Pós Graduação da UFSC. Vice-Líder do Grupo de Pesquisa C\&C - Cuidando e Confortando.

${ }^{2}$ Enfermeira. Doutora em Enfermagem. Membro do Grupo de Pesquisa Cuidando e Confortando - C\&C. Bolsista do Programa Nacional de Pós-Doutorado.

${ }^{3}$ Enfermeira. Doutoranda pelo Programa de Pós-Graduação em Enfermagem Universidade Federal de Santa Catarina - UFSC. Membro do Grupo de Pesquisa C\&C. Bolsista CNPq.

${ }^{4}$ Enfermeira. Doutoranda pelo Programa de Pós-Graduação em Enfermagem Universidade Federal de Santa Catarina - UFSC. Membro do Grupo de Pesquisa C\&C - PEN/ UFSC. Bolsista da Coordenação de Aperfeiçoamento de Pessoal de Nível Superior -CAPES.

${ }^{5}$ Enfermeira. Doutoranda pelo Programa de Pós-Graduação em Enfermagem da UFSC. Membro do Grupo de Pesquisa C\&C. Bolsista CAPES/REUNI.

Autor correspondente:

Recebido: 20/07/2011

Mariely Carmelina Bernardi

Aprovado: 10/11/2011

Universidade Federal de Santa Catarina

Rua Ipê Roxo, 1851 - 85420-000 - Corbélia-PR-Brasil

E-mail: marielybernardi@yahoo.com.br 


\section{INTRODUÇÃO}

Os enfermeiros que atuam na educação em enfermagem buscam refletir sobre suas práticas no cotidiano do ensino-aprendizado, pois encaminhar novos profissionais enfermeiros ao mercado de trabalho é um desafio contínuo. A formação de profissionais competentes, críticos, reflexivos e cidadãos que atuem tanto na área de formação quanto no processo de transformação da sociedade, é um dos compromissos e responsabilidades da educação superior ${ }^{(1)}$.

Os desafios apresentados no cotidiano do enfermeiro professor e dos alunos nos levam a pensar que propostas pedagógicas inovadoras podem ser estratégias interessantes na busca de caminhos que indiquem novas possibilidades de ensinar e aprender. A pedagogia crítica aponta para estas possibilidades, apresentando em seu arcabouço a construção de uma sociedade participativa e solidária, na qual o homem é o sujeito do desenvolvimento pessoal e social. Neste sentido, a escola possui seu papel na formação dos sujeitos, pois tem a tarefa de desvelar e compreender a realidade em que estão inseridos e, assim identificar os temas geradores de questionamentos, produzindo conhecimento, realizando a auto-formação na ação de suas reflexões ${ }^{(2)}$.

Pautado nesta forma de pensar, o curso de Graduação em Enfermagem de uma instituição pública de ensino superior do sul do Brasil busca, em seu fundamento educacional, expresso no Projeto Político Pedagógico e seu currículo, implementar estratégias de ensino-aprendizagem que propiciem aos sujeitos da prática pedagógica assumir posições como sujeitos ativos de seu aprendizado, e o educador como facilitador e mediador do processo.

O uso de metodologias ativas é visto como um instrumento facilitador e motivador do ensino-aprendizagem quando aproxima o aluno de enfermagem da realidade concreta e renova o olhar do docente sobre a ação ensinar e aprender ${ }^{(3)}$. Neste método o professor tem o papel fundamental de buscar subsídios para contribuir com o crescimento acadêmico que se concretiza no momento em que os alunos assumem-se como protagonistas desse processo de ensino-aprendizagem ${ }^{(4)}$.

Assim, este texto narra a vivência do ensino da temática cuidados de feridas, no estágio docência de quatro pós-graduandas. Analisando que o estágio docência é um quesito instituído para bolsistas da Coordenação de Aperfeiçoamento de Pessoal de Nível Superior (CAPES) e Conselho Nacional de Desenvol- vimento Científico e Tecnológico (CNPq), este relato justifica-se pela relevância que tais pós-graduandas dão à experiência de docência em seu processo de formação profissional. Considera-se que o preparo de enfermeiros para exercer esta função configura-se em importante instrumento de qualificação para os futuros docentes em Enfermagem, e a observação e descrição destas experiências pode proporcionar a outros profissionais a ampliação de suas habilidades neste processo de ensinar-aprender.

Trata-se, portanto, de um relato de experiência de quatro alunas bolsistas de um Programa de PósGraduação em Enfermagem, scricto senso, de uma universidade pública do sul do Brasil. A experiência ocorreu durante o estágio docência desenvolvido na disciplina de Fundamentos para o Cuidado Profissional do Curso de Graduação em Enfermagem, no segundo semestre de 2010. Foram desenvolvidas várias atividades de ensino-aprendizagem, sendo aqui descrita uma das que participaram as referidas alunas. O critério de inclusão dos sujeitos foi ser bolsista da CAPES ou CNPq e estar realizando o estágio de docência na referida disciplina no segundo semestre de 2010.

\section{A DISCIPLINA SEDE DA EXPERIÊNCIA: FUN- DAMENTOS PARA O CUIDADO PROFISSIONAL}

A disciplina de Fundamentos para o Cuidado Profissional, com 378 horas, acontece na terceira fase do Curso de Graduação em Enfermagem e objetiva ensinar o cuidado de enfermagem, extrapolando os aspectos técnicos e tratando o cuidado de maneira mais ampla, abordando as ações investigativas; o processo de trabalho, gerenciar e educar; o cuidado em Teorias de Enfermagem; metodologia de cuidado; semiologia e semiotécnica; ética e bioética.

Está estruturada em tutorias, nas quais a turma de alunos é dividida em grupos, em média com 12 alunos cada grupo de tutoria é conduzido de forma autônoma por um tutor, que é professor efetivo na universidade, cuja função é mediar, coordenar os trabalhos e discutir os conteúdos propostos a partir dos estudos independentes desenvolvidos pelos alunos, ou seja, dos temas previamente estudados. Compõe a tutoria os subgrupos de facilitação, conduzidos por professoras facilitadoras que acompanham, participam das discussões e desenvolvem as atividades teórico-práticas junto aos alunos. As atividades também são desenvolvidas em laboratório de Enfermagem para o aprendizado dos procedimentos de cuidado e, em vivências em cenários 
de prática quando atuam em unidades hospitalares. Outro momento rico em aprendizagem são as socializações, onde os alunos compartilham seus conhecimentos e suas descobertas com o restante de sua turma. As estagiárias docentes são inseridas na disciplina como professoras facilitadoras.

\section{ESTÁGIO DE DOCÊNCIA - UMA EXPERIÊNCIA ÍMPAR}

O Estágio de Docência é um momento de ensinoaprendizagem interessante para o pós-graduando pois aproxima-o com o contexto docente e suas nuances. Neste texto serão descritas as atividades desenvolvidas no grupo de tutoria em que as estagiárias atuaram.

\section{Momento de aprendizagem na tutoria}

$\mathrm{O}$ tema atendendo as necessidades de manutenção da integridade corporal -cuidados com feridas - avaliação de feridas, foi conduzido pelas professoras tutoras, facilitadoras e estagiárias docentes em seus respectivos grupos por 5 horas/aula, no dia 25 de agosto de 2010. Enquanto que, o tema escolha de cobertura para feridas, foi ministrado por uma professora convidada, por 5 horas/aula, no dia seguinte, para todos os grupos de tutoria. Na tutoria, optou-se em conjunto, pelo desenvolvimento do tema por meio de um jogo na forma de perguntas e respostas que recebeu o nome de "quiz fundamental". Uma das estagiárias responsabilizou-se pela condução das atividades.

Os alunos foram divididos em dois grupos de seis a partir da dinâmica de montagem de quebra cabeças. Duas figuras relacionadas a curativos foram dispostas em partes de quebra-cabeça e colocadas no chão com a face do desenho voltada para baixo, cada aluno escolheu uma peça e procurou os outros colegas que estavam com parte da figura, para juntos montarem o quebra-cabeça e formarem o grupo, os quais nomearam de "Band-aid" e "Fofoletes". Nesta dinâmica, várias questões foram apresentadas, dentre elas: quais são as funções da pele e qual a sua constituição? Quais as formas de classificação das feridas? O que deve ser avaliado em um paciente com ferida? Quais fatores influenciam na cicatrização das feridas? Cada questão permitia a discussão para aprofundamento junto à tutora e pós graduandas que desafiavam os alunos para a reflexão vinculando a teoria à prática. Após o "quiz", os alunos escreveram suas dúvidas em um papel e estes papeis foram depositados em uma caixinha, sendo respondidas em duplas, socializadas, discutidas e complementadas pelo grupo. Após, avaliaram a dinâmica como aprendizagem descontraída e participativa.

Esta vivência nos remete a pensar que o ensino pode e deve ser um momento de prazer e de seriedade simultaneamente. Estar em um ambiente que promove a troca e que valoriza a todos passa a ser fundamental no ensino. Neste sentido a utilização das metodologias ativas amplia habilidades de relacionamento pessoal, autonomia da aprendizagem e desenvolvimento do pensamento crítico $^{(5)}$.

\section{Momento de apredizagem no laboratório de enfermagem}

Este local configurou-se em um ambiente no qual os alunos da tutoria conheceram os materiais utilizados para a realização de curativos, bem como observaram a demonstração do procedimento pelos professores e, posteriormente realizaram em bonecos manequins. Este momento ocorreu por 5 horas/aula, no dia 30 de agosto de 2010.

Ao iniciar a aula, coordenada pela tutora do laboratório, os professores facilitadores demonstraram diferentes possibilidades do procedimento de curativos, bem como os materiais utilizados na técnica, e neste caso, uma das pós-graduandas também realizou a demonstração do procedimento, e ao mesmo tempo dialogou com os acadêmicos. Após este momento, abriu-se um espaço de discussão entre todos os presentes configurando um momento de troca de experiências e de esclarecimentos. Posterior à demonstração, os acadêmicos reuniram-se em pequenos grupos junto às professoras facilitadoras para assim, praticar o procedimento em bonecos e manusear os materiais. Este momento torna-se rico, pois no encontro em pequenos grupos se estabelecem relações que vão além da execução da técnica, onde as discussões pautam-se em ações de cuidado.

Estas ações que são estabelecidas no diálogo entre os sujeitos da prática pedagógica levam a crer que há um diferencial quando se busca a formação críticoreflexiva, na qual o aprender é o atributo fundamental nas relações entre os sujeitos envolvidos em interação no processo ensino-aprendizagem, através da participação ativa do estudante ${ }^{(6)}$. Esta vivência possibilitou perceber que o processo de aprendizagem do cuidado não se limita a preparar o conteúdo, mas também a ouvir a necessidade e estar atento às dificuldades dos alunos, re-planejar atividades e discutir sobre atitudes, valores e possibilidades de convivência em grupo, ao cuidado e à habilidade no uso das tecnologias ${ }^{(7: 301)}, \mathrm{o}$ que se configura em um desafio diário ao professor. 


\section{Momento deaprendizagem de cuidado: prática no hospital}

A prática dos curativos ocorreu a partir de 16 de setembro de 2010, quando os alunos, estagiárias docentes e professoras facilitadoras puderam colocar em prática o cuidado aprendido. A vivência desta aprendizagem no hospital universitário teve como objetivo proporcionar aos alunos a efetivação do ato de cuidar do paciente e de seus familiares. Contemplou ainda o convívio com os profissionais da saúde, não apenas a equipe de enfermagem, mas também a equipe multiprofissional que atuava naquele ambiente, onde o aluno permaneceu por um determinado período. Esta prática foi estruturada considerando a individualidade e o ritmo de aprendizagem de cada aluno. Nesta perspectiva, os alunos foram distribuídos primeiramente em duplas, e o professor facilitador em conjunto com a estagiária docente determinaram quais cuidados seriam prestados aos pacientes. Conforme avançava a autonomia do aluno, o mesmo passava a assumir os cuidados ao paciente individualmente, para que na medida em que desenvolvesse as ações de cuidado, exercitasse sua autonomia e responsabilidade.

Neste cenário, a prática de enfermagem assume cada vez mais os pressupostos instituídos pelas "inovações científicas e tecnológicas a que chegamos, e que, estão aí a exigir novas atitudes, novas condutas, novas formas de pensar e ser"(8:807). Os estagiários docentes têm a oportunidade de vivenciar as dificuldades dos acadêmicos, bem como seus momentos de superação e aprendizagem.

\section{CONSIDERAÇÕES FINAIS}

O estágio de docência é um momento ímpar para o processo de formação de pós-graduandos em enfermagem, tendo em vista, proporcionar o contato direto com as etapas propostas para o processo de ensinoaprendizagem dos alunos. Ao favorecer a aproximação com as experiências dos mesmos e seus mecanismos de enfrentamento a cada situação nova; amplia os olhares para a formação em enfermagem, percebendo que as metodologias de ensino inovam as condutas, a fim de que os profissionais e futuros profissionais possam, em suas práticas, exercitarem a reflexão, baseada no diálogo e, aprimorar o cuidado de enfermagem.

Acredita-se que ainda são necessários novos estudos que revelem a experiência de enfermeiros em seu processo de formação docente, tendo em vista que a enfermagem precisa de professores a cada dia mais qualificados e mais próximos da realidade de seus alu- nos, falando sua linguagem ensinando e aprendendo nos mais diversos contextos. Nesse sentido, este relato pode contribuir dando visibilidade ao processo de formação de enfermeiros docentes, pois socializar experiências é também uma forma de construir conhecimentos.

\section{REFERÊNCIAS}

1. Ito EE, Peres AM, Takahashi RT, Leite MMJ . O ensino de enfermagem e as diretrizes curriculares nacionais: utopia x realidade. Rev. esc. enferm. USP. 2006; 40(4):570-5.

2. Freire P. Pedagogia da autonomia: Saberes necessários à pratica educativa. 33a ed. São Paulo: Paz e Terra, 2006.

3. Costa CCC, Bezerra Filho JG, Machado MMT, Machado MFAS, Jorge AC, Furtado AAA, et al. Curso técnico de enfermagem do Profae-Ceará: a voz dos supervisores. Texto contexto enferm. 2008;17(4):70513.

4. SEBOLD LF, MARTINS FE, ROSA R, CARRARO TE, MARTINI JG, KEMPFER SS. Metodologias ativas: uma inovação na disciplina de fundamentos para o cuidado profissional de enfermagem. Cogitare enferm. 2010; 15(4):753-6.

5. Cogo ALP, Silveira DT, Pedro ENR, Tanaka RY, Catalan VM. Undergraduated nursing student's opinion about group work in online project. Rev. gaúcha enferm. 2010;31(3):435-41.

6. Silva KL, Sena RR. Nursing education: seeking criticalreflexive education and professional competencies. Rev. latino-am. enfermagem. 2006;14(5):755-61.

7. Prado ML, Reibnitz KS, Gelbcke FL. Learning to care: sensibility as a plasmatic element for critical-creative professional education in nursing. Texto contexto enferm. 2006;15(2):296-302.

8. Carvalho V. Caring, researching and teaching: meanings and implications of nursing practice. Rev. latino-am. enferm. 2005;12(5):806-15. 